\title{
Profil Tumor Solid pada Pasien Rawat Inap di Bagian KSM Ilmu Penyakit Dalam RSUP Prof. Dr. R. D. Kandou Manado Periode Januari 2013-Desember 2014
}

\author{
${ }^{1}$ Krisye M. Kandow \\ ${ }^{2}$ Linda W. A. Rotty \\ ${ }^{3}$ Harlinda Haroen \\ ${ }^{1}$ Kandidat Skripsi Fakultas Kedokteran Universitas Sam Ratulangi Manado \\ ${ }^{2}$ Bagian Ilmu Penyakit Dalam Universitas Sam Ratulangi Manado \\ Email: m.kandow_11_218@yahoo.com
}

\begin{abstract}
Solid tumor is an abnormal swelling in the human body caused by a number of diseases, such as malignancy (cancer). This was a descriptive retrospective study involving all medical record data of solid tumor patients treated in Prof. Dr. R. D. Kandou Hospital Manado from January 2013 through December 2014. The most frequently found tumor was breast cancer (181 people; $28.8 \%$ ) and the least one was nasopharyngeal cancer (6 patients; $1 \%$ ). The majority of patients were 50-59 years old (180 patients; $28.7 \%$ ) and the least found were 20-29 years old (7 patients; $1.1 \%$ ). Females (460 patients; $73.2 \%$ ) were more commonly found than males (168 patients; $26.8 \%$ ). The occupation of most patients was housewives (287 patients; $45.7 \%$ ), and the least found was university/high school students ( 3 patients; $0.5 \%$ ). The type of tumor according to gender was breast cancer in females (181 patients; $28.8 \%$ ) and most of the patients were aged 40-49 years old and 50-59 years old (each of 61 patients; 9.7\%). Conclusion: Solid tumor was most commonly found in females, aged 50-59 years old, and housewives; breast cancer had the highest percentage.
\end{abstract}

Keywords: solid tumor, carcinoma, mortality

\begin{abstract}
Abstrak: Tumor solid adalah bentuk benjolan yang tidak normal dalam tubuh, yang disebabkan oleh berbagai macam penyakit, antara lain keganasan (kanker). Penelitian ini bertujuan untuk mendapatkan profil tumor solid pada pasien rawat inap di Bagian KSM Ilmu Penyakit Dalam RSUP Prof. Dr. R. D. Kandou Manado periode Januari 2013-Desember 2014. Jenis penelitian ialah deskriptif retrospektif dengan menggunakan seluruh data rekam medis status pasien tumor solid yang dirawat di RSUP Prof. Dr. R. D. Kandou Manado periode Januari 2013-Desember 2014. Hasil penelitian memperlihatkan tumor terbanyak ialah karsinoma mammae (181 pasien; $28,8 \%$ ) dan yang paling sedikit karsinoma nasofaring (6 orang; $1 \%$ ). Sampel penelitian terbanyak berusia 50-59 tahun (180 pasien; 28,7\%) dan yang paling sedikit berusia 20-29 tahun (7 pasien; $1,1 \%)$. Sampel berjenis kelamin perempuan sebanyak 460 pasien $(73,2 \%)$ dan jenis kelamin lakilaki 168 pasien (26,8\%). Pekerjaan pasien yang tersering ialah sebagai ibu rumah tangga (287 pasien; 45,7\%) dan yang paling sedikit mahasiswa/pelajar (3 pasien; 0,5\%). Jenis tumor berdasarkan jenis kelamin ditemukan sebagian besar pasien perempuan menderita karsinoma mammae (181 pasien; 28,8\%), berusia 40-49 tahun dan 50-59 tahun (masing-masing 61 pasien; 9,7\%). Simpulan: Tumor solid lebih sering ditemukan pada jenis kelamin perempuan, kelompok usia 50-59 tahun, pekerjaan sebagai ibu rumah tangga; karsinoma mammae dengan persentase tertinggi.
\end{abstract}

Kata kunci: tumor solid, karsinoma, mortalitas 
Tumor solid adalah bentuk benjolan yang tidak normal (abnormal) dalam tubuh, yang disebabkan oleh berbagai macam penyakit, seperti penyakit keganasan. Secara umum keganasan ini disebut kanker. Jenis tumor solid diberi nama sesuai jenis sel-sel yang membentuknya. Sebagai contoh, yaitu: sarkoma terdiri atas fibrosarkoma, osteosarkoma, liposarkoma, kondrosarkoma, dan sarkoma jaringan lunak; sedangkan karsinoma terdiri dari karsinoma nasofaring, karsinoma laring, karsinoma tiroid, karsinoma lidah, karsinoma mammae, karsinoma paru, karsinoma gaster, karsinoma hati primer, karsinoma kolorektum, karsinoma pankreas, karsinoma ginjal, karsinoma prostat, karsinoma penis, karsinoma serviks uteri, karsinoma endometrium karsinoma ovarium, dan karsinoma vulva. ${ }^{1}$

Pada tahun 2007, kanker merupakan penyebab utama mortalitas di dunia (sekitar $13 \%$ dari seluruh penyebab mortalitas) dengan angka perkiraan sekitar 7,9 juta kematian. Jenis kanker tersering penyebab mortalitas tiap tahunnya berupa karsinoma paru (1,4 juta mortalitas/tahun), karsinoma lambung (866.000 mortalitas/tahun), kolon (677.000 mortalitas/tahun) dan karsinoma mammae (548.000 mortalitas/tahun). Pada laki-laki, jenis kanker tersering terdiri dari karsinoma paru, lambung, kolorektal, dan prostat sedangkan pada perempuan terdiri dari karsinoma mammae, paru, lambung, kolorektal, dan serviks. Sekitar $72 \%$ dari seluruh mortalitas kanker pada tahun 2007 terjadi di negara berpendapatan rendah sampai berpendapatan menengah. ${ }^{2}$

Sebanyak 1.596.670 kasus kanker baru dan 571.950 kematian akibat kanker yang diproyeksikan terjadi di Amerika Serikat pada tahun 2011. Diperkirakan bahwa sekitar 571.950 orang Amerika akan mati karena kanker, sesuai dengan data lebih dari 1500 kematian per hari. Kanker paru, prostat dan kolorektum pada laki-laki dan kanker paru, payudara, dan kolorektum pada perempuan terus menjadi penyebab paling umum kematian kanker. ${ }^{3}$

Menurut data Riskesdas tahun 2007, di Indonesia prevalensi tumor atau kanker ialah 4,3/1000 penduduk, dengan proporsi kejadian penyakit sebesar $10,2 \%$ dan berada pada urutan ke-7 penyebab kematian setelah tuberkulosis, hipertensi, perinatal dan diabetes melitus. ${ }^{4}$ Dampak penyakit kanker terhadap ketahanan sumber daya manusia di Indonesia sangat besar karena selain merupakan penyebab kematian dan kesakitan juga menurunkan produktivitas. $^{5}$

\section{METODE PENELITIAN}

Jenis penelitian ini ialah deskriptif retrospektif. Data diambil dari rekam medik pada periode Januari 2013 sampai Desember 2014 di Instalasi Rawat Inap RSUP Prof. Dr. R. D. Kandou Manado. Populasi dan sampel penelitian yaitu seluruh data pasien yang dirawat di Instalasi rawat inap RSUP.Prof.dr.R.D. Kandou Manado periode Januari 2013 sampai Desember 2014. Variabel penelitian yang diteliti yaitu jenis tumor, jenis kelamin, usia, dan pekerjaan. Data diolah secara manual dan disajikan dalam bentuk tabel berdasarkan variabel penelitian dan dianalisis sesuai hasil persentase.

\section{HASIL PENELITIAN}

Pada penelitian ini didapatkan karakteristik 628 sampel berdasarkan jenis kelamin, usia, pekerjaan, dan jenis tumor. Sebagian besar jenis tumor pasien yang dijadikan sampel penelitian ialah karsinoma mammae berjumlah 181 orang $(28,8 \%)$ dan yang paling sedikit karsinoma nasofaring berjumlah 6 orang (1\%) (Gambar 1)

Sebagian besar sampel penelitian berusia 50-59 tahun dengan jumlah 180 pasien $(28,7 \%)$ dan yang paling sedikit berusia 20-29 tahun dengan jumlah 7 pasien (1,1\%) (Gambar 2). Sampel berjenis kelamin perempuan berjumlah 460 orang $(73,2 \%)$ dan jenis kelamin laki-laki berjumlah 168 orang $(26,8 \%)$ (Gambar 3).

Sebagian besar pekerjaan pasien yang dijadikan sampel penelitian ialah sebagai ibu rumah tangga dengan jumlah 287 orang $(45,7 \%)$ dan yang paling sedikit mahasiswa/pelajar berjumlah 3 orang 
$(0,5 \%)$ (Gambar 4).

Hasil tabulasi silang jenis tumor berdasarkan jenis kelamin mendapatkan sebagian besar pasien perempuan mempunyai karsinoma mammae sebanyak 181 orang $(28,8 \%)$ (Gambar 5). Hasil tabulasi silang jenis tumor berdasarkan usia memperlihatkan sebagian besar pasien berusia 40-49 tahun dan 50-59 tahun mempunyai karsinoma mammae masingmasing sebanyak 61 orang $(9,7 \%)$ (Gambar 6). Hasil tabulasi silang jenis tumor berdasarkan jenis kelamin mendapatkan sebagian besar pasien dengan pekerjaan sebagai ibu rumah tangga mempunyai karsinoma mammae sebanyak 104 orang $(16,6 \%)$ (Gambar 7).

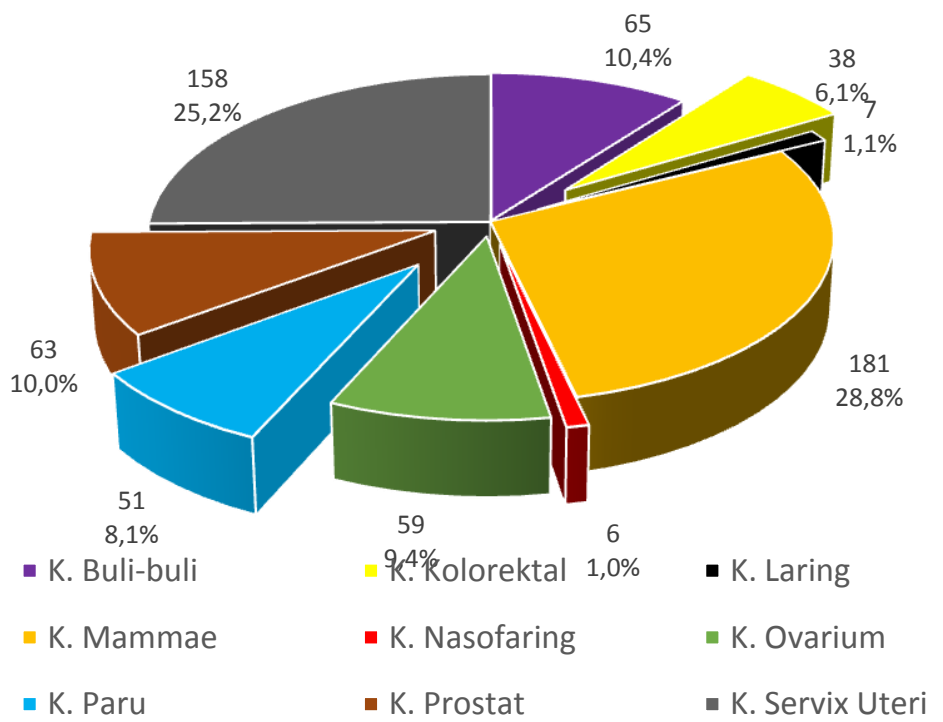

Gambar 1. Grafik distribusi berdasarkan jenis tumor

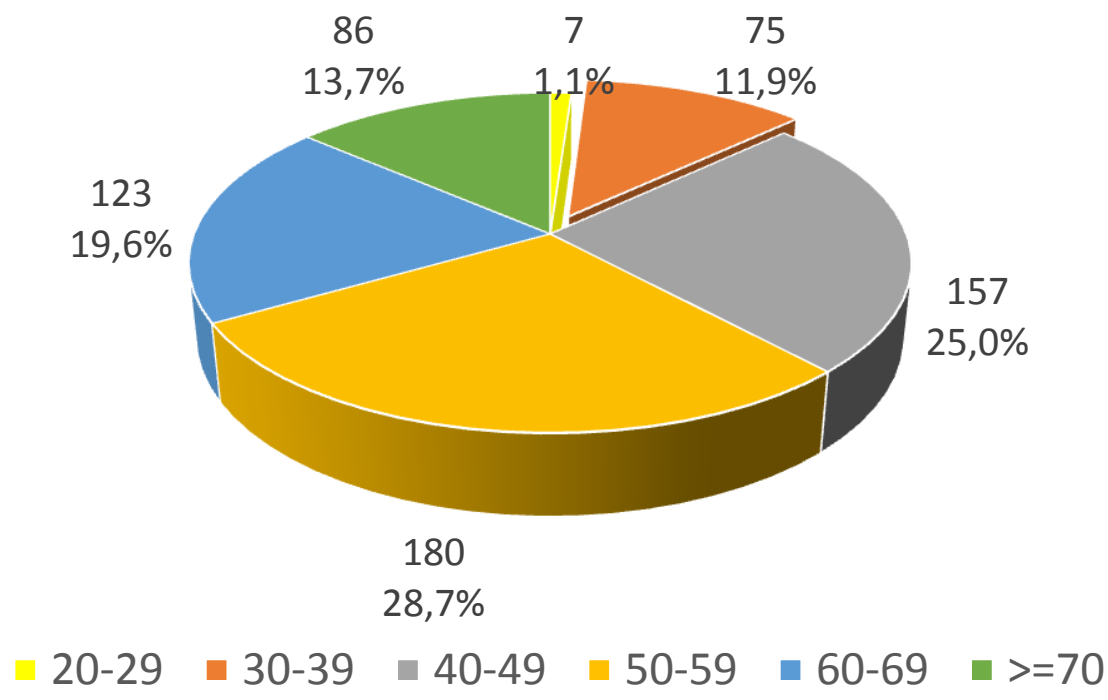

Gambar 2. Grafik distribusi berdasarkan usia 


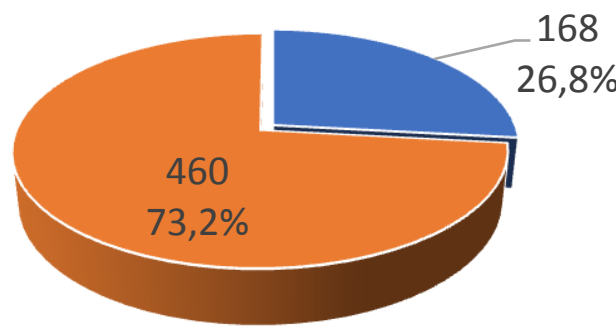

$$
\text { - Laki-laki " Perempuan }
$$

Gambar 3. Grafik distribusi berdasarkan jenis kelamin

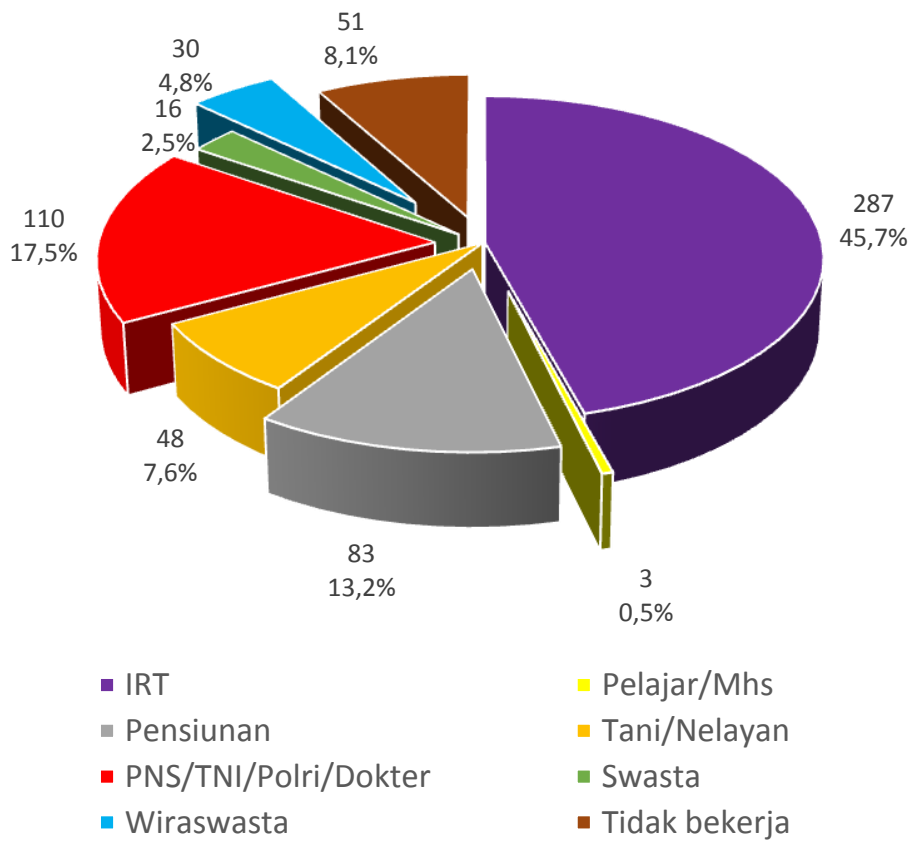

Gambar 4. Grafik distribusi menurut pekerjaan

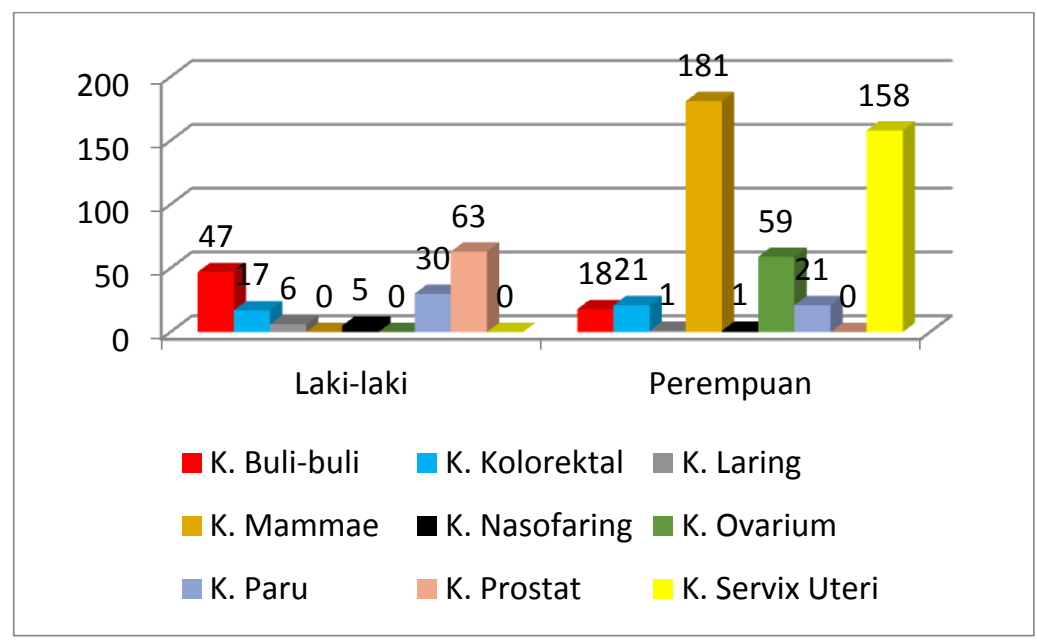

Gambar 5. Grafik distribusi jenis tumor berdasarkan jenis kelamin 


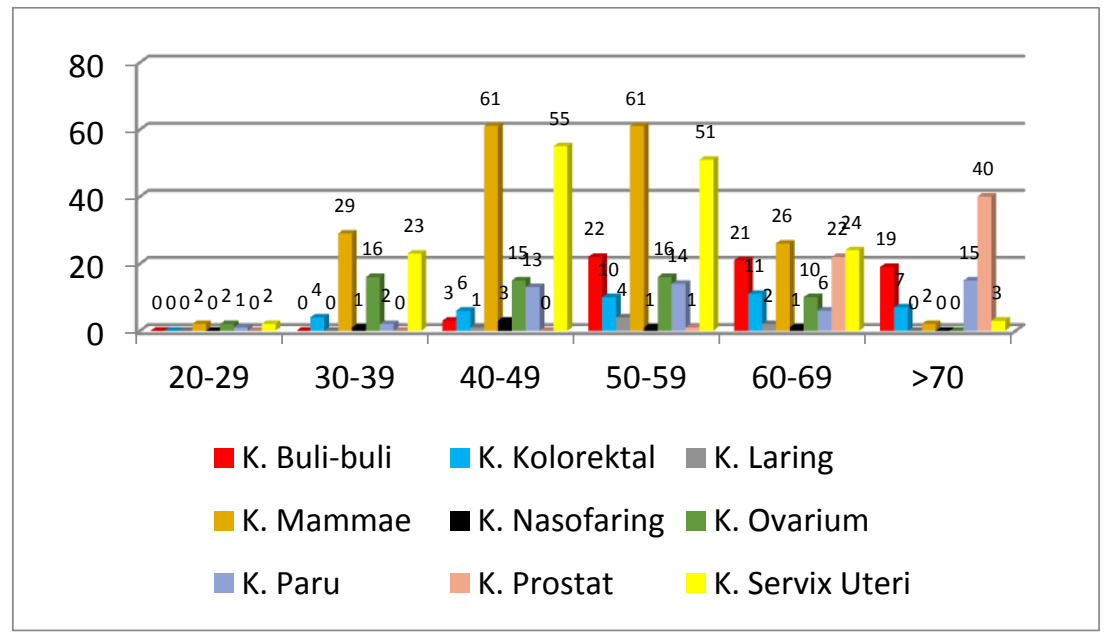

Gambar 6. Grafik distribusi jenis tumor berdasarkan usia

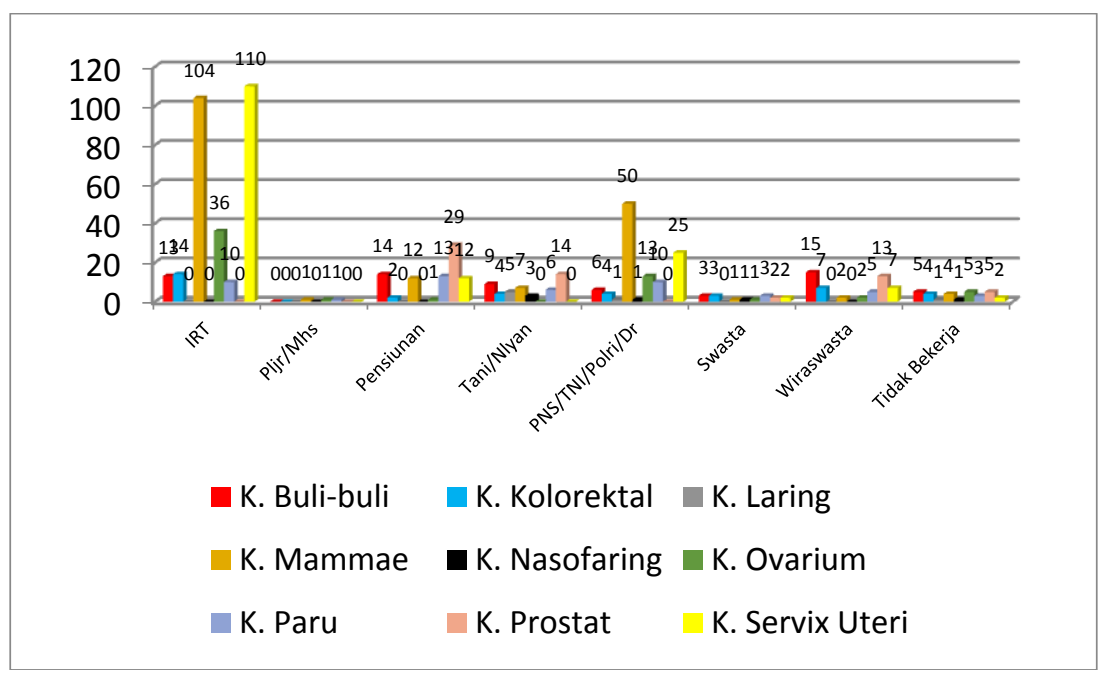

Gambar 7. Grafik distribusi jenis tumor berdasarkan pekerjaan

\section{BAHASAN}

Dari hasil penelitian yang dilakukan di bagian Instalasi Rawat Inap RSUP Prof. Dr. R. D. Kandou diperoleh data tentang jumlah pasien tumor solid selama periode Januari 2013-Desember 2014. Urutan penyakit dari frekuensi tertinggi sampai terendah yaitu sebagai berikut: karsinoma mammae 181 pasien $(28,8 \%)$, karsinoma serviks uteri 158 pasien $(25,2 \%)$, karsinoma buli-buli 65 pasien $(10,4 \%)$, karsinoma prostat 63 pasien (10\%), karsinoma ovarium 59 pasien $(9,4 \%)$, karsinoma paru 51 pasien $(8,1 \%)$, karsinoma kolorektal 38 pasien $(6,1 \%)$, karsinoma laring 7 pasien $(1,1 \%)$ dan karsinoma nasofaring 6 pasien $(1 \%)$.
Menurut kepustakaan selama 20 tahun terakhir tingkat insiden kejadian karsinoma mammae telah meningkat secara global, dengan tingkat tertinggi di negara-negara barat. Alasan untuk kecenderungan ini termasuk perubahan dalam pola makan, aktivitas menurun, dan pola reproduksi. ${ }^{6}$

Data yang diperoleh dari bagian Rekam Medik di RSUP. Prof.R.D Kandou Manado memperlihatkan pola penyebaran penyakit tumor solid. Kasus ini paling sering diderita oleh pasien dengan kelompok usia 50-59 tahun. Pada kelompok usia ini, jumlah pasien tumor solid sebanyak 180 pasien $(28,7 \%)$. Usia 50-59 tahun merupakan golongan usia yang paling sering menderita tumor solid. 
Menurut kepustakaan penyakit tumor solid sering terjadi dengan bertambahnya usia karena terjadi penurunan daya imunitas tubuh. $^{7}$

Dari hasil penelitian yang dilakukan, didapatkan pola penyebaran penyakit tumor solid berdasarkan jenis kelamin. Jenis kelamin yang paling sering mengalami kejadian tumor solid ialah perempuan dengan jumlah 460 pasien $(73,2 \%)$. Menurut kepustakaan, selain tumor pada organ kelamin dan organ yang berkaitan erat dengan hormon seks (misalnya payudara), insiden tumor pada perempuan ialah 40-70\% lebih banyak dari laki-laki. Dari semua jenis tumor, tumor saluran empedu dan tumor tiroid juga lebih sering ditemukan pada perempuan. ${ }^{8}$

Dari penelitian yang dilakukan, didapatkan pola penyebaran tumor solid berdasarkan pekerjaan. Sebagian besar yang menderita tumor solid ialah ibu rumah tangga dengan jumlah 287 pasien $(45,7 \%)$. Jenis tumor yang banyak diderita oleh ibu rumah tangga ialah karsinoma mammae. Hasil penelitian lain menunjukkan bahwa tidak terdapat hubungan antara pekerjaan dengan kanker payudara pada wanita. $^{7}$

\section{SIMPULAN}

Berdasarkan hasil penelitian dan bahasan dapat disimpulkan bahwa tumor solid lebih banyak ditemukan pada perempuan, kelompok usia 50-59 tahun, pekerjaan sebagai ibu rumah tangga, dan jenis tumor karsinoma mammae.

\section{SARAN}

Perlu dilakukan penataan sistem rekam medis perlu dilakukan guna menjamin tersedianya data yang berguna untuk penelitian baik terhadap kasus tumor solid maupun tumor lainnya.

\section{DAFTAR PUSTAKA}

1. Sudoyo AW, Setiyohadi B, Alwi I, Simadibrata MK, Setiati S. Buku Ajar Ilmu Penyakit Dalam Jilid 2 (4th ed). Jakarta: Interna Publishing, 2009; p.1035-40.

2. World Health Organization. The global burden of disease 2004, update. Geneve: WHO, 2008. [cited 2015 Oct 30]. Available from: http://www.WHO.com.

3. American Cancer Society. Cancer facts \& figures 2008. Atlanta, Ga: American Cancer Society; 2008. [cited 2015 Nov 05]. Available from: http://www.cancer.org.

4. Wijaya MA. Hasil Riset Kesehatan Dasar, Kementrian Kesehatan RI, 2007. [cited 2015 Nov 12]. Available from: http://www.riskesda.com.

5. Departemen Kesehatan, Survei Kesehatan Nasional. Laporan studi mortalitas 2001. Depkes R I Jakarta, 2002. [cited 2015 Nov 10]. Available from: http://www.riskesda.com.

6. Dawood S, Broglio K, Gonzalez-Angulo AM, Buzdar AU, Hortobagyi GN, Giordano SH. Trends in survival over the past two decades among white and black patients with newly diagnosed stage IV breast cancer. J Clin Oncol. 2008;26(30):4891-8.

7. Rini I, Gondhowiardjo SA. Faktor-faktor resiko yang berpengaruh terhadap kejadian kanker payudara wanita. Basic Science of Oncology (Ilmu Onkologi Dasar). Jakarta: Fakultas Kedokteran UI, 2010; p. 369-74.

8. Price SA, Wilson LM. Patofisiologi Konsep Klinis Proses-proses Penyakit Volume 1 (6th ed). Jakarta: EGC, 2006; p. 139-46. 